\title{
Idiopathic horseshoe-like macular tear: a case report
}

This article was published in the following Dove Press journal:

International Medical Case Reports Journal

28 July 2016

Number of times this article has been viewed

\author{
Masaomi Kubota' \\ Tomohiro Shibata' \\ Hisato Gunji' \\ Hiroshi Tsuneoka ${ }^{2}$ \\ 'Department of Ophthalmology, The \\ Jikei University School of Medicine \\ Kashiwa Hospital, Chiba, ${ }^{2}$ Department \\ of Ophthalmology, The Jikei University \\ School of Medicine, Tokyo, Japan
}

Correspondence: Masaomi Kubota Department of Ophthalmology, The Jikei University School of Medicine Kashiwa Hospital,

163-I Kashiwashita, Kashiwa City, Chiba 227-8567, Japan

Tel +8I 47164 IIII (ext. 358I)

Fax +8I4 7I64 II97

Email omiomi7725@jikei.ac.jp
Background: Although a few cases with idiopathic horseshoe-like macular tear have been reported, the mechanism remains unknown and a standard treatment has yet to be determined.

Objective: To report the outcome for a patient with idiopathic horseshoe-like macular tear who underwent vitreous surgery.

Case report: A 65-year-old man with no previous injury or ophthalmic disease presented with abnormal vision in his left eye. Best-corrected visual acuity was 0.8 in the right and 0.3 in the left, and the relative afferent pupillary defect was negative. Ophthalmoscopy revealed a horseshoe-like tear on the temporal side of the macula in the left eye. The tear size was 0.75 disc diameters (DD). Optical coherence tomography showed that the focal retinal detachment reached the fovea. A few days after the first visit, there was no longer adhesion of the flap of the tear to the retina and the tear size had increased to $1.5 \mathrm{DD}$. The patient underwent vitreous surgery similar to large macular hole surgery, with the tear closure repaired using the inverted internal limiting membrane flap technique with $20 \%$ SF6 gas tamponade. Although the tear decreased to $0.5 \mathrm{DD}$ after the surgery, complete closure of the tear was not achieved.

Conclusion: While cases with horseshoe-like macular tear following trauma and branch retinal vein occlusion have been reported, to the best of our knowledge, this is the first reported idiopathic case. In the present case, there was expansion of the tear until the patient actually underwent surgery. If vertical vitreous traction indeed plays a role in horseshoe-like macular tears, this will need to be taken into consideration at the time of the vitreous surgery in these types of cases.

Keywords: horseshoe-like macular tear, vitreous surgery, retinal detachment, vitreous traction

\section{Introduction}

Both the mechanism and treatment of horseshoe-like macular tear have yet to be definitively determined. Moreover, only a few cases with macular tear have been reported in the literature (Table 1$).{ }^{1-3}$ In these reported cases, secondary macular tear was observed after branch retinal vein occlusion (BRVO) or blunt ocular trauma. At the present time, however, there have been no reports of an idiopathic macular tear.

The purpose of our current study was to report the details and outcome of a patient with idiopathic horseshoe-like macular tear who underwent vitreous surgery.

\section{Case report}

In May 2014, a 65-year-old man developed abnormal vision in his left eye and presented to our hospital a few weeks after the initial presentation. Prior to this development, he had been physically well and had not had any history of ocular disease or 
Table I A few cases with macular tear have been previously reported in the literature. Our current case is the first report of an idiopathic case

\begin{tabular}{|c|c|c|c|c|c|c|}
\hline Case & Age/sex & Cause & Tear diameter & Treatment & Closure/disclosure & $\begin{array}{l}\text { BCVA pre-I } \\
\text { postoperative }\end{array}$ \\
\hline Current case & $65 M$ & None & $\begin{array}{l}0.75 \rightarrow 1.5 \mathrm{DD} \\
\text { (expanded) }\end{array}$ & $\begin{array}{l}\text { Vitrectomy + ILM invert } \\
+ \text { SF6 }\end{array}$ & Disclosure & $0.3 / 0.2$ \\
\hline Karim-Zade et al' & $53 M$ & BRVO & $0.75 \mathrm{DD}$ & Vitrectomy + C3F8 & Closure & $0.1 / 0.1$ \\
\hline Karaca et $\mathrm{a}^{2}$ & $21 M$ & Trauma & $0.75 \mathrm{DD}$ & Observation & Closure & C.f./c.f. \\
\hline Goel et $\mathrm{al}^{3}$ & $18 M$ & Trauma & $1.0 \mathrm{DD}$ & Vitrectomy + C3F8 & Closure & C.f. $/ 0.25$ \\
\hline
\end{tabular}

Abbreviations: BCVA, best-corrected visual acuity; M, male; DD, disc diameter; ILM, internal limiting membrane; SF6, Sulfur Hexafluoride 20\% gas tamponade; BRVO, branch retinal vein occlusion; C3F8, Octafluoropropane 16\% gas tamponade; c.f., count finger.

previous injury. On initial examination, best-corrected visual acuity was 0.8 in the right and 0.3 in the left eye. Intraocular pressure was $15 \mathrm{mmHg}$ in the right and $10 \mathrm{mmHg}$ in the left eye. Light reflex was rapid in both eyes and the relative afferent pupillary defect was negative. Slit-lamp examination showed cataract (Emery-Little classification I or II) in both eyes.

Ophthalmoscopy revealed a horseshoe-like tear on the temporal side of the macula in the left eye (Figure 1A). The tear size was 0.75 disc diameter. There was adhesion between the retinal tear and the vitreous. Fluorescein angiography (VX-10i; Kowa Co., Ltd., Nagoya, Japan) revealed a nonperfusion area and the absence of any findings of retinal vein occlusion (Figure 1B).
Spectral-domain optical coherence tomography (Cirrus HD-OCT, Carl Zeiss Meditec AG, Jena, Germany) using the HD 5-line raster scan protocol (horizontal scan of $6 \mathrm{~mm}$ ) revealed a focal retinal detachment that reached the fovea in the left eye (Figure 1C). No obvious abnormality was seen in the right eye. We scheduled vitreous surgery for the patient 2 weeks after the initial evaluation. A few days after the first visit there was no longer adhesion of the flap of the tear to the retina and the tear size had increased to 1.5 disc diameter (Figure 2A).

After obtaining written informed consent for the surgery, the patient underwent vitreous surgery that was similar to the technique for large macular hole (MH) surgery. ${ }^{4}$ The patient provided written informed consent to be part of this case

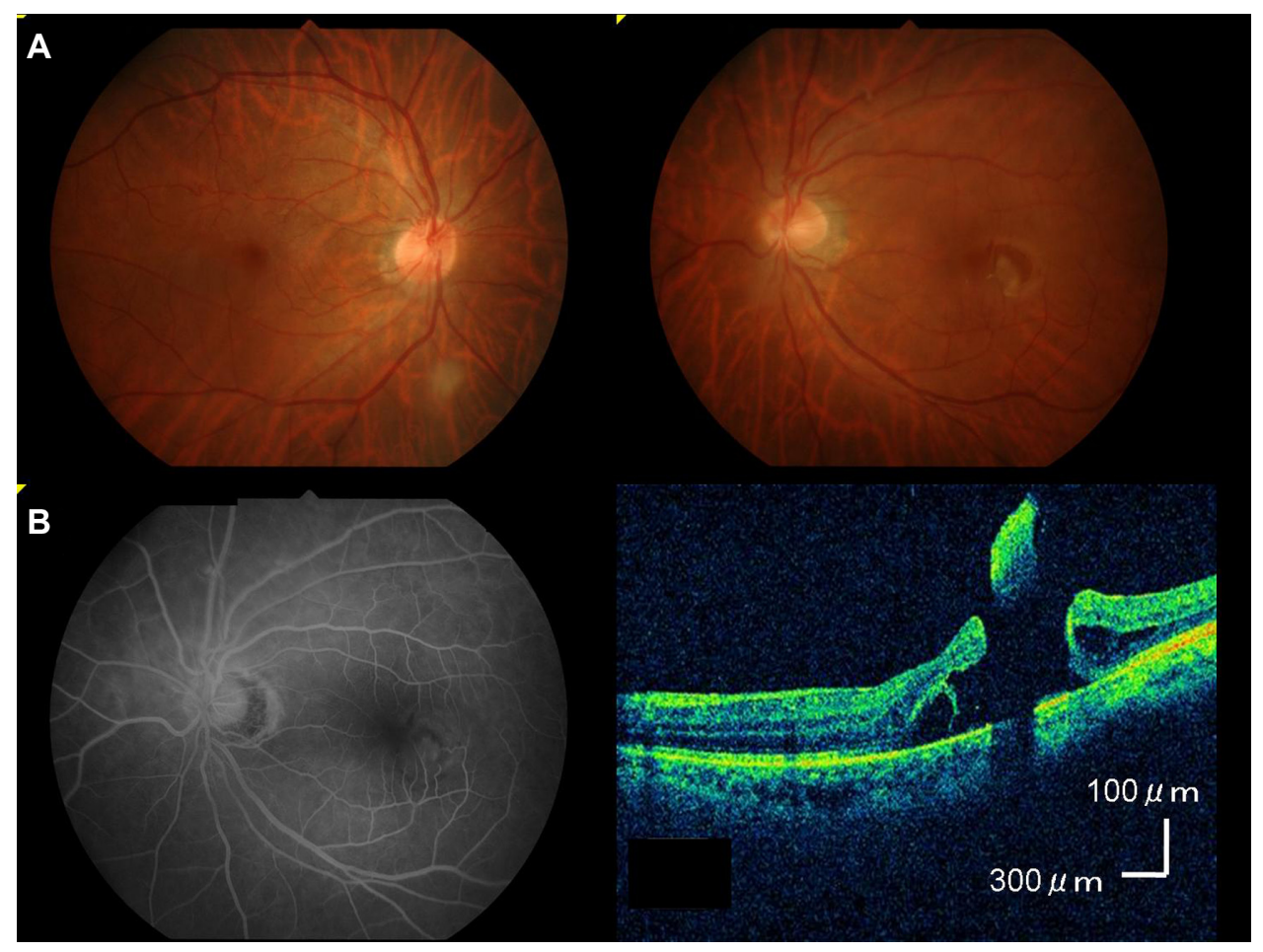

Figure I (A) Ophthalmoscopy revealed a horseshoe-like tear on the temporal side of the macula in the left eye. (B) Fluorescein angiography revealed a non-perfusion area and that there was no retinal vein occlusion. (C) Spectral-domain optical coherence tomography revealed the focal retinal detachment in the left eye reached the fovea. 


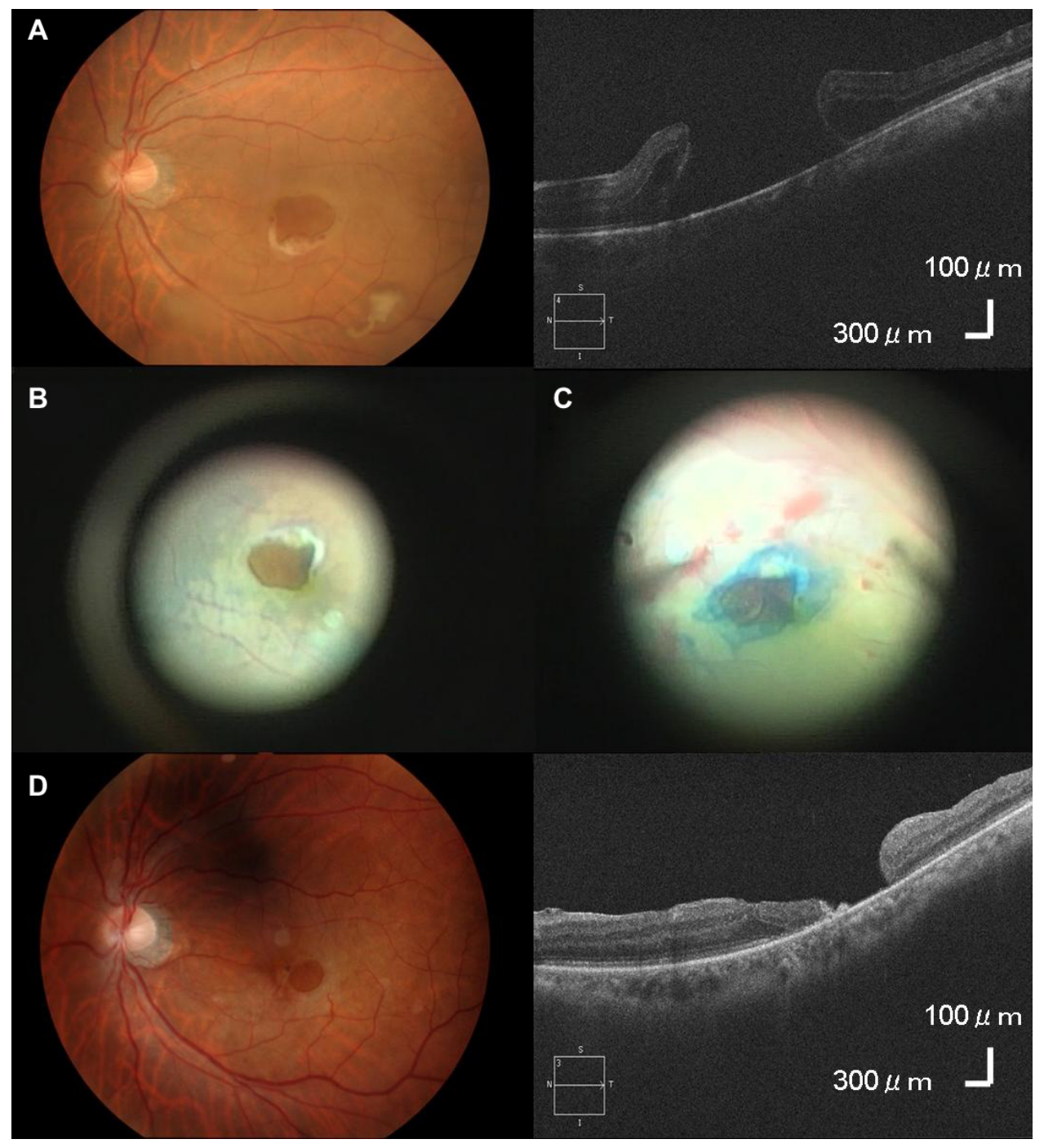

Figure 2 (A) A few days after the first visit, there was no longer adhesion of the flap of the tear to the retina and the tear size had increased to I.5 disc diameters. (B) Before the surgery, the macular tear size was I.5 disc diameters. (C) In order to close the tear, we performed the inverted internal limiting membrane flap technique with $20 \%$ SF6 gas tamponade. (D) Although the disc diameter of the tear after the surgery decreased to 0.5 disc diameters, complete closure of the tear was not achieved.

study. Ethical approval was deemed unnecessary by The Jikei University School of Medicine Institutional Review Board, as in cases where a procedure is part of a patients standard care, following the principals of the Declaration of Helsinki is recommended. Therefore this was undertaken here. The patient provided written informed consent to be part of this case study. To close the tear, we performed the inverted internal limiting membrane flap technique with $20 \%$ SF6 gas tamponade (Figure $2 \mathrm{~B}$ and $\mathrm{C}$ ). Although the tear decreased to 0.5 disc diameter after the surgery, it did not achieve complete closure (Figure 2D). At 1 month after the surgery, the retina around the tear was attached, and the best-corrected visual acuity was 0.2 in the left eye.

\section{Discussion}

This case highlighted two important issues. First, even if patients do not have past ophthalmic histories, such as
BRVO or blunt ocular trauma, an idiopathic horseshoe-like macular tear can occur. The cases with retinal hole or tear following BRVO or blunt ocular trauma have been previously reported..$^{1-3}$ In 1997, Ikuno et $\mathrm{al}^{5}$ reported that the differentiation between two types of retinal breaks that occur after BRVO in eyes with retinal detachment could be defined as retinal holes with or without vitreoretinal traction. In 2003, Leibovitch et $\mathrm{al}^{6}$ reported finding lamellar $\mathrm{MH}$ due to macular edema following BRVO.

In 2007, Karim-Zade et al $^{1}$ were the first to report a case of horseshoe-like macular tear after BRVO. They concluded that besides vitreous traction, chronic macular edema and retinal ischemia following BRVO were also factors that contributed to the formation of the macular tear. In one patient who underwent vitrectomy with $16 \% \mathrm{C} 3 \mathrm{~F} 8$ gas tamponade, there was reattachment of the tear and the visual acuity was maintained. 
On the other hand, in 2014, Karaca et $\mathrm{al}^{2}$ reported a case of horseshoe-like macular tear that occurred after blunt ocular trauma. Furthermore, there have been many cases in the literature where spontaneous closure occurred after traumatic $\mathrm{MH}$. However, this has not been reported in previous cases with macular tear. In the current case, the horseshoe-like macular tear observed at the initial visit appeared to spontaneously close a month after the initial evaluation. Since this patient did not have any previous ophthalmic histories of BRVO or blunt ocular trauma, we diagnosed this case as an idiopathic horseshoe-like macular tear.

Gass $^{7}$ examined $\mathrm{MH}$ formation and proposed that the prefoveal vitreous cortex caused anterior traction detachment of the retina, which subsequently caused tangential traction. Similarly, vitreomacular traction syndrome has also been reported to be caused by vertical vitreous traction. ${ }^{8}$ When there is an incomplete posterior vitreous detachment, this exerts persistent anterior traction on the fovea. Therefore, it has been shown that visual improvement can be achieved in most cases of $\mathrm{MH}$ and vitreomacular traction syndrome by relieving vertical vitreous traction. ${ }^{9,10}$ Although, in the current case, we could not definitively determine why the tear formed beside the parafovea. Karaca et $\mathrm{al}^{2}$ supposed that if vitreous attachment is not equal at all sides of macula, sudden traction exerted on the macula could result in a macular tear. We speculated that for some reason there was adhesion or sudden traction between the retinal tear and vitreous.

This case further highlighted the fact that horseshoe-like macular tears can expand within only a few days. Unfortunately, the macular tear in our patient expanded until the actual surgery after which the tear did not completely close, despite performing surgery. In contrast to the MH and vitreomacular traction syndrome cases that are caused by anteriorposterior traction, in the horseshoe-like macular tear cases, there is strong adhesion or traction near the fovea that causes diagonal traction to the retina. Therefore, these tears can split and expand similar to a peripheral retinal tear. If our patient had immediately undergone vitreous surgery, it is quite likely that the tear would not have expanded, thereby leading to a complete closure of the macular tear after the surgery.

\section{Conclusion}

In conclusion, an idiopathic macular tear can occur and expand within a period of several days. To the best of our knowledge, this is the first report of an idiopathic case with retinal detachment. Further investigations and an accumulation of additional data will be needed in order to definitively determine the cause of the idiopathic horseshoe-like macular tear. In our current case, the tear continued to expand until the patient underwent surgery. If vertical vitreous traction indeed plays a role in horseshoe-like macular tears, this will need to be taken into consideration at the time of vitreous surgery in these types of cases.

\section{Disclosure}

The authors report no conflicts of interest in this work.

\section{References}

1. Karim-Zade K, Bilgic A, Bartz-Schmidt KU, Gelisken F. Horseshoe-like macular tear following recurrent branch retinal vein occlusion. Graefes Arch Clin Exp Ophthalmol. 2007;245(8):1221-1223.

2. Karaca U, Durukan HA, Mumcuoglu T, Erdurman C, Hurmeric V. An unusual complication of blunt ocular trauma: a horseshoeshaped macular tear with spontaneous closure. Indian J Ophthalmol. 2014;62(4):501-503.

3. Goel N, Sharma R, Mandal M, Choudhry RM. Posttraumatic horseshoeshaped macular tear. Indian J Ophthalmol. 2014;62(11):1103-1104.

4. Michalewska Z, Michalewski J, Adelman RA, Nawrocki J. Inverted internal limiting membrane flap technique for large macular holes. Ophthalmology. 2010;117(10):2018-2025.

5. Ikuno Y, Tano Y, Lewis JM, Ikeda T, Sato Y. Retinal detachment after branch retinal vein occlusion: influence of the type of break on the outcome of vitreous surgery. Ophthalmology. 1997;104(1):27-32.

6. Leibovitch I, Azmon B, Pianka P, AlsterY, Loewenstein A. Macular hole secondary to branch retinal vein occlusion diagnosed by Retinal Thickness Analyzer. Ophthalmic Surg Lasers Imaging. 2003;34(1):53-56.

7. Gass JD. Idiopathic senile macular hole: its early stages and pathogenesis. 1988. Retina. 2003;23(6 Suppl):629-639.

8. Yamada N, Kishi S. Tomographic features and surgical outcomes of vitreomacular traction syndrome. Am J Ophthalmol. 2005;139(1):112-117.

9. Gaudric A, Haouchine B, Massin P, Paques M, Blain P, Erginay A. Macular hole formation: new data provided by optical coherence tomography. Arch Ophthalmol. 1999;117(6):744-751.

10. Yooh HS, Brooks HL Jr, Capone A Jr, L'Hernault NL, Grossniklaus HE. Ultrastructural features of tissue removed during idiopathic macular hole surgery. Am J Ophthalmol. 1996;122(1):67-75.
International Medical Case Reports Journal

\section{Publish your work in this journal}

The International Medical Case Reports Journal is an international, peer-reviewed open-access journal publishing original case reports from all medical specialties. Previously unpublished medical posters are also accepted relating to any area of clinical or preclinical science. Submissions should not normally exceed 2,000 words or

\section{Dovepress}

4 published pages including figures, diagrams and references. The manuscript management system is completely online and includes a very quick and fair peer-review system, which is all easy to use. Visit $\mathrm{http}: / / \mathrm{www}$.dovepress.com/testimonials.php to read real quotes from published authors. 